\title{
Immunohistological characterisation of acute herpes simplex virus infection of lumbar dorsal root ganglia in the rat
}

\author{
J. M. BLONDEAU*§, F. Y. AOKI* $†$ and J.I. NAGY $\ddagger$
}

Departments of Medical Microbiology and Infectious Disease, $\uparrow$ Pharmacology and Therapeutics and $\ddagger$ Physiology, University of Manitoba, Winnipeg, Manitoba, Canada

\begin{abstract}
Summary. After inoculation of herpes simplex virus (HSV) into the dorsal skin of the hind paw of rats, HSV antigen was detected in dorsal root ganglion neurones by immunohistochemistry. Antigen was first detected 2 days after inoculation. Between 2 and 4 days after inoculation, numerous small-type unmyelinated neurones gave positive staining reactions for HSV antigens. Necrosis of neuronal cells was evident by 4 days. Antigen was not detected 6 or 9 days after inoculation. Immunohistological studies of co-cultivated ganglia removed from the infected monolayers, immediately after cytopathic effect first appeared or $24 \mathrm{~h}$ later, uniformly revealed virus antigen staining of small-type unmyelinated neuronal cells.
\end{abstract}

\section{Introduction}

Herpes simplex virus (HSV) causes primary, latent and recurrent infections of man and experimental animals. ${ }^{1-3} \mathrm{~A}$ unique feature of this virus is its ability to establish latency within neurones of the sensory ganglia. In 1923, Goodpasture and Teague ${ }^{4}$ postulated, and Kristensson et al. ${ }^{5}$ demonstrated experimentally, that HSV spreads within axon(s) to the central nervous system (CNS) from skin or mucosal sites of infection. Since that time, numerous investigations have studied the spread of HSV within the peripheral nervous system (PNS) and the CNS in animals experimentally infected with this virus. Cook and Stevens ${ }^{6}$ demonstrated the presence of herpesspecific fluorescence in neuronal and satellite cells of mouse dorsal root ganglia after foot pad inoculation. Furthermore, electronmicroscopy has revealed virus particles within the neurones. Itoyoma et al..$^{7}$ found that 2 days after inoculation of the cornea of mice with HSV type-1, isolated neurones within the trigeminal ganglion were positive for HSV and infected satellite cells were present in ring-like arrays around infected and apparently uninfected neurons; by 8 days, HSV antigen was still detectable in neurones but not in satellite cells. We have recently characterised acute and latent HSV type-1 infections in dorsal root ganglia of a new rat model. ${ }^{3}$ We now present detailed photographic data of immunohistological studies of

Received 23 June 1992; accepted 29 Sept. 1992.

$\S$ Present address and address for correspondence: St Paul's Hospital (Grey Nuns) of Saskatoon, Department of Microbiology, 1702-20th Street West, Saskatoon, Saskatchewan, Canada S7M OZ9. acute and latent infections of rat dorsal root ganglia after peripheral inoculations with HSV type-1.

\section{Materials and methods}

\section{Rats}

Sprague-Dawley outbred female rats (Charles River Canada Inc., St Constant, Quebec) weighing 70-100 g were used. They were from a strain known to be free of HSV antibody. Rats were assigned to experimental and control groups by a table of random numbers. Rats (four cage) were maintained on laboratory chow and water ad libitum. The housing temperature was $20^{\circ}-21^{\circ} \mathrm{C}$ with a $12 \mathrm{~h}$ on/off light schedule. Standards of general husbandry of the Canadian Council for Animal Care were maintained throughout this study.

\section{Virus strain}

HSV-76 virus, determined to be type-1 by restriction endonuclease analysis, was used for this study. ${ }^{8}$ The virus was propagated in Vero cells in mycoplasmaand antibiotic-free Minimal Essential Medium (MEM) (Flow Laboratories) with fetal bovine serum (FBS; Gibco) $5-10 \%$ inactivated for $30 \mathrm{~min}$ at $56^{\circ} \mathrm{C}$. When infected monolayers showed $70-80 \%$ cytopathic effect (CPE), cell cultures were freeze-thawed twice and the suspension was clarified by low speed centrifugation and passed through a $0 \cdot 22-\mu \mathrm{m}$ filter (Nalgene). Small volumes were stored frozen at $-70^{\circ} \mathrm{C}$. The virus was titrated by calculating the median tissue culture infectious dose (TCID50) on Vero cells in Costar 24-well plates (Costar). ${ }^{9}$ The titre 
of the virus stocks was $\log _{10} 8.33 \mathrm{TCID} 50 / \mathrm{ml}$. Virus was used after the fourth and fifth passage following isolation from the patient. For some experiments, stock virus was diluted in MEM or phosphate-buffered saline (PBS).

\section{Inoculation of rats}

Rats were anaesthetised with pentobarbitol sodium (Abbot Laboratories) $5 \mathrm{mg} / 100 \mathrm{~g}$ injected intraperitoneally and $20 \mu \mathrm{l}$ of stock virus solution was injected into the dorsum of the hind paw unilaterally or bilaterally with a Hamilton microlitre syringe and a 30-gauge needle. Control animals were inoculated with PBS or MEM. All animals were examined twice daily for 28 days for signs of neurological abnormality and to determine time to death.

\section{Recovery of HSV by culture of sensory ganglia}

Rats were killed with pentobarbitol sodium $15 \mathrm{mg} / 100 \mathrm{~g}$ injected intraperitoneally. Once anaesthetised, rats were bled by cardiac puncture for plasma and serum samples which were stored at $-20^{\circ} \mathrm{C}$. Fourth, fifth and sixth lumbar dorsal root ganglia were removed and analysed for HSV as follows. By use of a dissecting microscope at $40 \times$ magnification, the spinal cord was exposed and the appropriate lumbar ganglia were identified and removed. Ganglia were placed individually in vials containing $1.5 \mathrm{ml}$ of MEM supplemented with FEBS $3 \%$ and antibiotics (penicillin $100 \mathrm{IU} / \mathrm{ml}$, gentamicin $250 \mu \mathrm{g} / \mathrm{ml}$ and mycostatin $25 \mathrm{IU} / \mathrm{ml}$ ) and incubated for $24 \mathrm{~h}$ at $37^{\circ} \mathrm{C}$ in $\mathrm{CO}_{2} 5 \%$ in humidified air. ${ }^{10}$ Ganglia were then explanted individually on to monolayers of human neonatal foreskin fibroblast cells and left undisturbed for $48 \mathrm{~h}$ at $37^{\circ} \mathrm{C}$ in $\mathrm{CO}_{2} 5 \%$ in humidified air. ${ }^{10}$ All tubes were coded before examination for CPE, to control observer bias. Monolayers were checked daily with inverted microscope at $40 \times$ magnification for the appearance of typical HSV CPE which was considered indicative of the presence of HSV. Cultures not showing CPE after 21 days were discarded as negative.

The characteristics of infection after unilateral injection of $6.4 \times 10^{6}$ TCID50 of HSV-1 in the dorsal skin of the hind paw were reported previously. ${ }^{3}$

\section{Immunohistochemistry}

Rats were anaesthetised with $0.5-1 \mathrm{ml}$ of chloral hydrate $25 \%$ injected intraperitoneally. Immediately following anaesthesia and before death, rats were placed on ice, the heart was exposed and the right atrium was severed. A 15-gauge needle was inserted into the left ventricle and the rat was perfused with $50 \mathrm{ml}$ of ice-cold prefix consisting of distilled $\mathrm{H}_{2} \mathrm{O}$ $80 \%$, saline $(0.15 \mathrm{M} \mathrm{NaCl}) 10 \%, 0.5 \mathrm{M}$ phosphate buffer $10 \%, \mathrm{NaNO}_{2} 0 \cdot 1 \% \mathrm{w} / \mathrm{v}$ and heparin 100 units. Following this prefix, the rats were perfused with icecold fixative consisting of distilled $\mathrm{H}_{2} \mathrm{O} 80 \%$ and $0.5 \mathrm{M}$ phosphate $20 \%$ with paraformaldehyde $4 \% \mathrm{w} / \mathrm{v}$. The spinal cord was then exposed by dissection and removed along with the left and right fourth, fifth and sixth lumbar ganglia. In some rats, the brain was also removed. Tissues were placed in fixative overnight and transferred the following day to $0 \cdot 1 \mathrm{M}$ phosphate $(\mathrm{pH} 7 \cdot 4)$ containing sucrose $15 \% \mathrm{w} / \mathrm{v}$ for 1 day.

Tissues were mounted in O.C.T. mounting medium on a metal chuck placed on dry ice. The chuck with tissue was placed at $-26^{\circ} \mathrm{C}$ for $30 \mathrm{~min}$ to allow temperature equilibration, and cryostat sections were cut at a thickness of $15 \mu \mathrm{m}$ and mounted on to gelatincoated microscope slides. Slides were removed from $-26^{\circ} \mathrm{C}$ one at a time and a border of plastic cement was placed around the tissue to contain the antibody solution. The tissue was covered with a polyclonal rabbit antibody to HSV (Dimension Laboratory), diluted 1 in 1000 in PBS containing Triton $0.3 \%$ and bovine serum albumin (BSA) $1 \%$, incubated for $48 \mathrm{~h}$ at $4^{\circ} \mathrm{C}$ in a humidified chamber and then rinsed for two 30-min periods in PBS containing Triton $0.3 \%$. The sections were then covered with goat anti-rabbit immunoglobulin (Miles Scientific) at a dilution of 1 in 20 in PBS containing Triton $0.3 \%$ and BSA $1 \%$, incubated for $1 \mathrm{~h}$ at room temperature and rinsed with PBS containing Triton $0.3 \%$ as above. Rabbit immunoglobulin conjugated to peroxidase anti-peroxidase (PAP; Miles Scientific) was then added at a dilution of 1 in 250 in PBS containing Triton $0.3 \%$ and BSA $1 \%$. The tissue was incubated for $1 \mathrm{~h}$ at room temperature and then rinsed as follows: $15 \mathrm{~min}$ with PBS containing Triton $0.3 \%$; two rinses for $15 \mathrm{~min}$ each in $50 \mathrm{~mm}$ Tris; submerged in diaminobenzadine substrate (DAB) $20 \mathrm{mg}$ in $100 \mathrm{ml}$ of $50 \mathrm{~mm}$ Tris containing $15 \mu \mathrm{l} / 100 \mathrm{ml}$ of $\mathrm{H}_{2} \mathrm{O}_{2} 30 \%$ for $4-6 \mathrm{~min}$; and two rinses for $15 \mathrm{~min}$ each in $50 \mathrm{~mm}$ Tris. The tissue was then air-dried overnight at room temperature. It was dehydrated further by immersion in alcohol 70, 80 and $95 \%$ for $1.5 \mathrm{~min}$ each, alcohol $100 \%$ for $1.5 \mathrm{~min}$ twice, and xylene for $3 \mathrm{~min}$ twice. Coverslips were applied with Lipshaw mounting medium and the sections were examined with an Olympus microscope.

The same technique was applied to ganglia at various times after initiation of co-cultivation to obtain information on ganglion cell types infected with HSV; 296 ipsilateral lumbar ganglia removed 31-37 days after subcutaneous injection of $6.4 \times 10^{6}$ TCID50 of HSV in $20 \mu 1$ into the dorsum of the hind feet were co-cultivated as described above. After cocultivation for 2-9 days, nine ganglia were removed from culture immediately after detection of HSV-CPE and three ganglia were removed 1 day later and processed for immunohistological examination as above.

Uninfected control tissue was treated by the same procedure as infected tissue. Infected control tissue was also treated as above but without the primary HSV antibody. Both sets of control tissues gave uniformly negative results. 

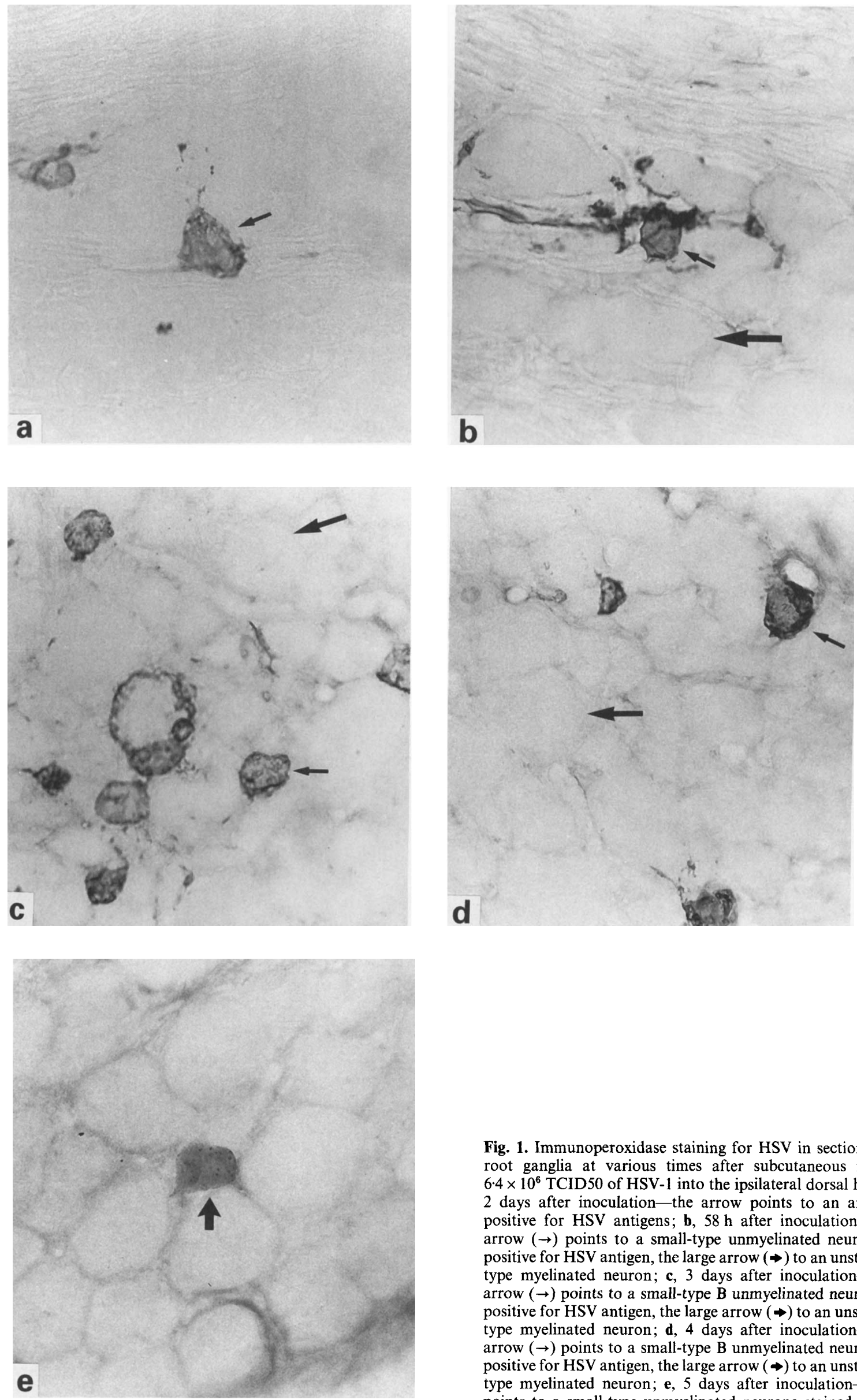

Fig. 1. Immunoperoxidase staining for HSV in sections of dorsal root ganglia at various times after subcutaneous injection of $6.4 \times 10^{6}$ TCID50 of HSV-1 into the ipsilateral dorsal hind paw : a, 2 days after inoculation-the arrow points to an area staining positive for HSV antigens; $\mathbf{b}, 58 \mathrm{~h}$ after inoculation-the smal arrow $(\rightarrow)$ points to a small-type unmyelinated neurone stained positive for HSV antigen, the large arrow $(\rightarrow)$ to an unstained largetype myelinated neuron; c, 3 days after inoculation-the small arrow $(\rightarrow)$ points to a small-type B unmyelinated neurone stained positive for HSV antigen, the large arrow $(\rightarrow)$ to an unstained large type myelinated neuron; $\mathbf{d}, 4$ days after inoculation-the small arrow $(\rightarrow)$ points to a small-type B unmyelinated neurone stained positive for HSV antigen, the large arrow $(\rightarrow)$ to an unstained largetype myelinated neuron; e, 5 days after inoculation-the arrow points to a small-type unmyelinated neurone stained positive for HSV antigen $(\times 400)$. 


\section{Results}

\section{Immunohistological studies}

HSV antigen was not detected in lumbar ganglia 1 day after inoculation. After 2 days, nerve fibres gave positive results for virus antigen in at least. one ganglion of three rats tested (fig. 1a). Between 2.4 and 4 days, viral antigen was detected in numerous smalltype neurons (fig. 1b, c and d). At 2-4 days, one or two cells/section were stained positive and at 4 days, 1-20 cells/section were stained positive for antigen. Necrosis of neuronal cells was evident by day 4 (fig. 1d). By day 5 (fig. 1e), only one ganglion had positive
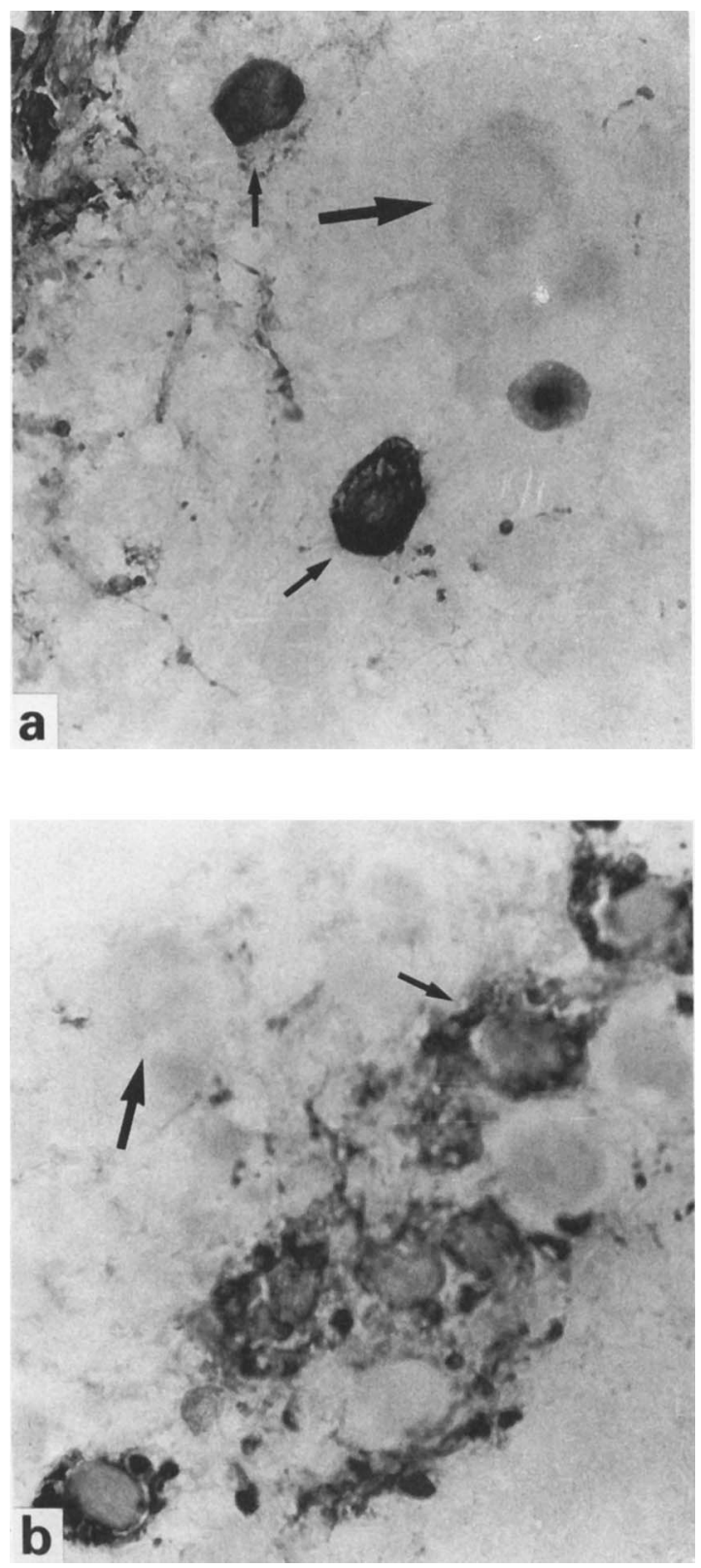

Fig. 2. Immunoperoxidase staining for $\mathrm{HSV}$ in sections of lumbar ganglion (a) immediately after or (b) 1 day after observation of HSV-CPE in co-cultivated monolayers. The small arrows $(\rightarrow)$ point to small-type unmyelinated neurons stained positive for HSV antigen, the large arrows $\rightarrow$ to unstained large-type myelinated neuron $(\times 400)$. cells and at days 6 and 9, no antigen was detected (data not shown).

Immunohistological studies of co-cultivated ganglia removed from the infected monolayers, either immediately after CPE first appeared or $24 \mathrm{~h}$ later, showed uniform virus antigen staining-primarily of small-type unmyelinated neuronal cells (figs. 2a and b). In addition, there was consistent staining around the peripheral edge of the ganglia corresponding to the tissue closest to the infected monolayer. Ganglia removed from monolayers not showing CPE after 5, 6 and 7 days of co-cultivation gave negative results for HSV antigens (data not shown).

\section{Discussion}

Subcutaneous injection of HSV into the dorsum of the hind paw of rats yielded predictable acute and latent HSV dorsal root ganglion infection that conformed to our current knowledge of this infection in otherwise healthy human subjects. Our selection of the hind foot site permitted injection without undue extravasation of virus suspension, and the delivery of an appropriate volume, the importance of which has been noted by others. ${ }^{11}$ The present rat model of human cutaneous infection had a number of characteristics. $^{3}$ Infection was initiated by subcutaneous injection of $6.4 \times 10^{6}$ TCID50 of HSV-1 in $20 \mu \mathrm{l}$ into the dorsum of a hind foot. HSV was detectable at the injection site up to 4 days after injection. Data from immunohistological studies and a sciatic nerve transection experiment indicated that HSV migrated centripetally within the sciatic nerve, causing lytic infection, primarily in the neuronal cell bodies of small unmyelinated fibres in lumbar sensory ganglia. The number of cells infected was maximal 3-4 days after inoculation (1-20 cells/section). In $25 \%$ of animals, paralysis of the ipsilateral leg developed and $30 \%$ died, presumably due to encephalitis caused by cephalad HSV migration along the central neuraxis. Virus also migrated centrifugally into the contralateral lumbar sensory ganglia but not into the skin of the contralateral hind foot. HSV complement-fixing antibody was detected in all rats - in some as early as the second day after infection. By the sixth day, HSV antigen was not detected in lumbar sensory ganglia but demonstration of lytic HSV infection in these ganglia at day 28 by co-cultivation indicated that infection had become latent.

Immunohistological staining of acutely infected rat ganglia (within 2-5 days) showed that primarily smalltype unmyelinated neurones were displaying HSV antigens, as reported previously by Cook and Stevens in mice. ${ }^{6}$ However, they also reported infection of satellite cells and found that Schwann cells associated with myelinated axons were free of virus while those associated with non-myelinated axons were infected. Differences in virus susceptibility between neurones and supporting cells have also been seen by others and may be due to species differences. ${ }^{12}$ 
Lytic infection in sensory ganglia of mice and rats was evident up to 8 days and 5 days, respectively. ${ }^{6,7,13}$ However, it is unclear whether this occurs in all human cutaneous HSV infection. In all animal models, an apparently asymptomatic latent infection of sensory ganglia follows the productive phase. This has been characterised by the appearance of HSV CPE in monolayer substrates on which ganglia are co-cultivated, at a longer interval than is required during cultivation of productively infected ganglia. In our system, the mean interval for HSV CPE to appear was $63 \%$ greater around ganglia removed 28 days after HSV inoculation than around those removed after 4 days. $^{3}$

Immunohistological staining of latently infected ganglia associated with CPE in co-culture demonstrated an apparent central role, once again, for smalltype unmyelinated neurones in amplification of HSV antigen in rat ganglia. However, staining primarily of small-type neurones for HSV antigens was not observed in studies in mice. ${ }^{10}$ Although there is little doubt that the virus recovered in cell culture originated from the co-cultivated ganglia, we cannot be certain whether the neurones staining positive for $\mathrm{HSV}$ antigen represented cells that were displaying reactivated virus or were cells that had been re-infected from the infected monolayer. However, ganglia removed from infected monolayers either immediately or $24 \mathrm{~h}$ after recognition of CPE exhibited similar types of neurones stained positive for HSV antigens.

The present immunohistological observations of acute, latent and reactivated virus in vitro suggest that mainly small unmyelinated neurones are involved in the replication of $\mathrm{HSV}$ infection during acute and reactivated stages of infection of rats in vitro. However, we were unable to establish whether the small-type neurones are those in which latent virus resides. Small neurones could allow virus replication (permissive) while another cell type(s) harbours the latent virus (non-permissive). Permissive and non-permissive cells may either release virus to permissive cells during reactivation or they may become permissive after receiving signals from the skin, following the application of an activating or triggering stimulus.

We gratefully acknowledge the technical assistance of Lynn Polson and the clerical assistance of Janice Flynn and Deb Leciuk. This work was supported in part by a grant from the Medical Research Council of Canada to J.I.N.

\section{References}

1. Stanberry LR. Herpesvirus latency and recurrence. Prog Med Virol 1986; 33: 61-77.

2. Klein RJ. The pathogenesis of acute, latent and recurrent herpes simplex virus infections. Arch Virol 1982; 72: 143-168.

3. Blondeau JM, Aoki FY, Galvin GB, Nagy JI. Characterization of acute and latent herpes simplex virus infection of dorsal root ganglia in rats. Lab Anim 1991; 25: 97-105.

4. Goodpasture EW, Teague O. Transmission of the virus of herpes febrilis along nerves in experimentally infected rabbits: J Med Res 1923; 44: 139.

5. Kristensson K, Lycke E, Sjöstrand J. Spread of herpes simplex virus in peripheral nerves. Acta Neuropathol 1971; 17: $44-53$.

6. Cook ML, Stevens JG. Pathogenesis of herpetic neuritis and ganglionitis in mice: evidence for intra-axonal transport of infection. Infect Immun 1973; 7: 272-288.

7. Itoyoma Y, Sekizawa T, Openshaw H, Kogure K, Kuriowa Y. Immunocytochemic localization of herpes simplex virus antigens in the trigeminal ganglia of experimentally infected mice. J Neurol Sci 1979; 66: 67-75.
8. Blondeau JM, Embil JA, McFarlane ES. Apparent stability of herpes simplex virus genomes isolated from primary and recurrent infections and dorsal root ganglia in the mouse. $J$ Med Microbiol 1988; 27 : 291--296

9. Reed LJ, Muench H. A simple method of estimating fifty percent endpoints. Am J Hyg 1938; 27 : 493-497.

10. Blondeau JM, Embil JA, McFarlane ES, James H, Henry M, Sangalang VE. Visualization of replicating herpes simplex virus in cervical dorsal root ganglia of mice following explant of individual ganglion onto susceptible indicator cells. J Med Virol 1986; 20 : 341-346.

11. Roizman B, Sears AE. An inquiry into the mechanisms of herpes simplex virus latency. Annu Rev Microbiol 1987; 41: 543-571.

12. Dillard SH, Cheatham WJ, Moses HL. Electron microscopy of zosteriform herpes simplex infection in the mouse. Lab Invest $1972 ; 26: 391-402$.

13. Kristensson K, Svennerholm B, Persson L, Vahlne A, Lycke E. Latent herpes simplex virus trigeminal ganglionic infection in mice and demyelination in the central nervous system. $J$ Neurol Sci $1979 ; 43$ : 253-263. 